A Phenomenological Exploration of the Childfree Choice in a Sample of Australian

\title{
Women
}

Joanne Doyle

Julie Ann Pooley

Edith Cowan University

Lauren Breen

Curtin University 


\begin{abstract}
Choosing not to have children is considered a deviation from cultural norms, particularly the dominant pronatalist discourse; this is especially so for women. However, little research has documented the experience of Australian women who have consciously chosen to remain childless. Ten voluntarily childfree women participated in unstructured interviews about their choice and its ramifications. The data analysis revealed three broad themes - the experiences and processes of making the choice; the ongoing effects of their choice, ranging from support and acceptance to pressure and discrimination; and no regret as the women described engaging in meaningful, generative activities that contributed to society. Keywords: Adults, Women's health, Qualitative methods, Phenomenology, Family
\end{abstract}




\section{A Phenomenological Exploration of the Childfree Choice in a Sample of Australian}

\section{Women}

Women who choose to remain childfree are a relatively new and growing cohort in industrialised countries due to the advent of contraception, an increase in workforce participation, and a reduced power differential between the sexes (Abma \& Martinez, 2006; Rowland, 2007). A survey of 7,448 Australian women aged from 22 to 27 years revealed that 9.1\% desire to remain childfree (Lee \& Gramotnev, 2006). The most recent national figures on voluntary childlessness revealed that $8 \%$ of women were voluntarily childless and predicted that, if expected fertility rates for 2000 continued into the future, $24 \%$ of women who have not yet reached the end of their reproductive years would be without children (Australian Bureau of Statistics, 2000).

Choosing to remain childless tends to place women outside the constraints of sociocultural expectations underpinned by pronatalism (Park, 2005), which encourages an increase in birth rate and reinforces the socio-political, familial and religious obligations of producing children for the good of the country and future generations (Rowlands \& Lee, 2006). Pronatalism means that women who choose to opt out of childbearing are viewed as challenging the 'natural' role of women and rejecting the fundamental essence of the feminine identity in a pronatalist society (Gillespie, 2000; Mollen, 2006). Given these contextual pressures, the investigation of women's choice to remain childfree is important in considering its potential effects on their health and wellbeing.

Women choosing childlessness also challenge the developmental path of womanhood (Hird \& Abshoff, 2000). For instance, an analysis of marriage and family textbooks produced from 1950 to 2000 illustrated that the depictions of childless adult were mostly negative, and voluntarily childfree adults were characterised more disapprovingly than the involuntarily 
childfree (Chancey \& Dumais, 2009). An analysis of media representations of childlessness in the United Kingdom revealed selfishness as an explanation of the phenomenon (Giles, Shaw, \& Morgan, 2009). Similarly, surveys of parents, students, and the general public demonstrate that women without children are considered to be selfish, deviant, undesirable, empty, and ultimately unfeminine (Gillespie, 2000; Kelly, 2009; Koropeckyj-Cox \& Pendell, 2007; Letherby, 2002; Rowlands \& Lee, 2006; Vinson, Mollen, \& Smith, 2010). As an example of the latter, the act of giving birth remains a symbolically important rite of passage reinforcing a woman's gender and social identity (Koropeckyj-Cox, Romano, \& Moras, 2007); woman and mother become largely one and the same.

The emergence of 'mother' as a social identity occurred through a complex interaction of multiple influences. From a scientific perspective, psychology and modern medicine have had a powerful influence in promoting motherhood as central to womanhood and perpetuating the deficit status of childfree women (Lee \& Gramotnev, 2006; Mollen, 2006; Park, 2002). In addition, political influences advocate the traditional nuclear family with its associated gender roles. For example, successive Australian governments have supported the pronatalist perspective with a Baby Bonus payable on the birth of a child and the provision of Family Tax Benefits to parents. In encouraging a boost to that country's birth rate, then Treasurer Peter Costello proclaimed, 'One [child] for the husband, one [child] for the wife, and one [child] for the country' (Carmichael \& Whittaker, 2007, p. 140) and the 2007 election was contested using the rhetoric of working families (Younane, 2008). The current Australian Prime Minister is often criticised for being unmarried and childless by choice (Gregg, 2011). Religious influences from the predominant Judeo-Christian beliefs that underpin Western culture saw womanhood as heterosexual, fertile, life-giving, and fecund (Gillespie, 2000). Even the current discussion of the choice to remain childfree is often explored using language that reinforces a perceived deficit or deviance of childfree women, 
for example, non-mother, without children, and childless (Gillespie, 1999; Kelly, 2009; Park, 2005). We have chosen to use the terms childless and childfree interchangeably but we acknowledge that the former may reinforce a deficit identity and latter bolster the stereotype concerning dislike of children and/or mothers.

The choice to 'forgo' motherhood and deviate from accepted social norms can be viewed through the lens of developmental theory. Erikson's (1963) generativity versus stagnation stage of development related to the years of middle adulthood when most women reach the end of their reproductive years. In this stage, adults who did not become parents, or adopt a leadership role in society, would not reach their full potential and instead would be become psychologically stagnant. However, empirical research shows little to no differences in psychological adjustment between women with and without children. Callan (1987) demonstrated little difference in the psychological adjustment of the voluntarily childfree compared to parents. A study of 678 Australian women aged from 22 to 27 years demonstrated little social or psychological differences when compared to their peers who desire children (Lee \& Gramotnev, 2006). Additionally, one study of 289 childless adults and 2,218 parents in the United States demonstrated no difference in the generativity development and psychological wellbeing of childfree women and mothers (Rothauff \& Cooney, 2008). Dykstra and Hagestad (2007) summarised the research literature on childfree adults' socioeconomic status, health, and social networks by declaring, 'Childless older adults did not emerge as the sad bunch they often are assumed to be' (p. 1523).

However, there are some differences - childfree women tend to be more highly educated, have little or no religious affiliation, hold non-traditional sex roles, report a higher commitment to their careers, and are more likely to live in urban areas than women with children (Cwikel, Gramotnev, \& Lee, 2006; DeOllos \& Kapinus, 2002; Somers, 1993). Childfree women also oppose the idea that normal adult development categorically includes 
motherhood and they do not see themselves as maladjusted (Gillespie, 2000). Voluntarily childfree women reject the notion of motherhood being instinctual and central to their identities (Carmichael \& Whittaker, 2007; Gillespie, 2000, 2003). Furthermore, childfree women may characterise childbearing as a burden demanding a sacrifice of time, energy, and identity, and encompassing a social duty to which they do not wish to adhere (Gillespie, 2003).

The majority of studies have focused on women with fertility issues rather than voluntarily childfree women, and therefore the differentiation between women freely choosing childlessness and those influenced by circumstance remains obscured (Hird \& Abshoff, 2000; Carmichael \& Whittaker, 2007). Furthermore, past research has tended to neglect the subjective experience of women who are voluntarily childless and there is little Australian research on the experiences of women who have chosen to not have children. As such, the research question was what are the experiences of Australian women choosing to be childfree?

\section{Methodology}

With interpretivism as the foundational paradigm, the intent of the study was to implement a phenomenological approach to understanding the choices and resulting experiences of voluntarily childless women. Phenomenology is the study and understanding of the subjective truth of another's perspective of the world and related meaning they have derived from their perceptions (Willis, 2007). A phenomenological approach allowed us to explore women's experiences of 'being-in-the-world' within relationship to self, to others, and to her choice of being childfree (Becker, 1992). One member of the research team is childfree by choice and the other two members each has two children; thus, as a research team, we occupy insider and outsider perspectives on the phenomenon of study, enabling a 
rigorous approach to reflexivity (Mauthner \& Doucet, 2003) in interpreting the women's stories.

$\underline{\text { Sample }}$

Ten women were interviewed for the study. The age range of participants was 32 to 53 years $(M=43.7, S D=5.93)$. Younger women were not sampled because they are more likely than older women to change their childbearing preferences (Heaton, Jacobson \& Holland, 1999). All participants were heterosexual and seven were in a partnered relationship (married or de facto) at the time of interview. A university degree had been obtained by half of the women with the others having completed year ten or above in high school. All the women were employed in paid work and were engaged in various careers including office administration, teaching, workforce planning and development, and management. Eight women had no religious affiliation; however seven described having spiritual beliefs.

\section{Materials and Procedure}

The study was approved by a university human research ethics committee. The participants were a convenience sample recruited through a snowball sampling method beginning with the first author's networks and broadening out to the participants' networks. Despite the limitations of snowball sampling, attempts were made to access a diverse sample of women. Inclusion criteria were that the women were at least 30 years of age and had chose to remain childfree. Potential participants were contacted and, if they met the criteria and provided their informed consent, they were interviewed in person by the first author.

The interviews were unstructured using open-ended questions and were one to two hours in duration. The interview guide consisted of open-ended questions on a range of topics including roles and identities (e.g., How would you describe yourself? How would you describe what it means to be a woman?), their choice to be childless (e.g., When did you know you didn't want children? Do you think anything could change your decision to not 
have children?), and relationships with others (e.g., How has your choice influenced your relationships with friends and family? How do you think you are perceived by others?). The questions were used as a guide only, as a flexible approach to questioning was adopted to ensure each woman's unique story emerged through its telling (Moustakas, 1994). All interviews were audio-recorded. The participants were assured that their identities would be confidential and data would be de-identified.

$\underline{\text { Data Analysis }}$

In order to capture the essence of each woman's experience, a reflective thematic analysis was the basis for data assimilation that consisted of a four-step process (Becker, 1992). First, each transcription was the focus of an in-depth analysis that concentrated on the 'experience of the other', the words, meanings and salient features unique to each participant. Themes were highlighted through writing key words in the transcript margins. Questions that elicited thematic information the defining events that led to her choice, the important aspects of her story, and how the different themes fitted together to influence her choice.

Second, upon identification of themes, a thematic version was created for each participant through electronically cutting and pasting from the original transcript. The emerging themes were edited and listed using the person's own words. These were then clustered into common themes or categories that did not include any overlapping or repetitive statements. The clustered themes were used to develop textural descriptions of the experience.

Third, interrelated themes were identified to make one trend. A summary portrait of each woman's experience was written in the first author's own words. The other authors read some transcripts and the draft interpretations. Differences in interpretations were considered and discussed until all authors were confident that the interpretations reflected the data. Finally, the summary portraits were taken to a higher level of generalisation. From each 
summary, common themes were identified and reordered to create a structural description of the essential qualities inherent in a woman's choice not to have children. These themes are illustrated with quotes from the interview transcripts. To protect the participants' identities, pseudonyms are used.

\section{Findings and Interpretations}

The choice to remain childfree elucidated three themes: (a) the choice - the experience of either a defining event or childhood influences that were the catalyst for the proactive choice, (b) the consequence - the ongoing effects of their choice, ranging from support and acceptance to pressure and discrimination, and (c) no regret - the acceptance of their decision.

\section{The Choice}

The majority of women reported making their choice at a relatively early age. Women who make the choice early are described as early articulators (Macklin, 1980). Some knew children were not an option: 'I've never, ever really wanted kids' (Cathy) and 'even when I was a young girl, I sort of knew then I wasn't going to have children' (Lynn). Others reported defining events in their childhood and adolescence, such as travel and illness, which broadened their perspective about raising children. For example, Julie reported:

I was probably 13 to 15 , around that age because we did it [visited an orphanage in Mexico] for a few years, that impact was just massive. None of those kids had homes - none of them, you know - and they were just the greatest people. They gave us, my sister and I, they gave us Christmas presents and we were just like 'what are they doing that for?' They had nothing, we had everything. That made a huge impact. I knew then. I used to say to mum 'oh I'm not going to have kids'. So it's never really changed. 
On the other hand, some women described their decision as being influenced by traumatic experiences such as being a witness to or a victim of violence in the family home. These women expressed strong views about dissatisfaction with their childhood and wanted to stop generational cycles of abuse, which supports previous research demonstrating that traumatic childhood experiences left women wanting to stop generational legacies and not reenact the same scenarios in their adult relationships (Carmichael \& Whittaker, 2007). The women recognised that they did not want to put any child through what they had experienced. As Kim explained:

As a result of his [father's] abusive childhood and what he off-loaded onto me, I did not want to do that to my children as well. I just didn't think it fair to bring a life, a whole fresh new life, into the world and beat the crap out of it emotionally and or physically.

Four women spoke of perceiving themselves as not emotionally mature enough or as lacking the necessary life skills to have children. Candice reported a sense of not being old enough, of still feeling very young inside even into her late 30s while others stated they either were not emotionally equipped or 'wasn't sure I had the skills to be any different, to do better' (Lynn). They recognised the immense responsibility parenthood demanded and they believed they would not have been equipped adequately. Seccombe (1991) suggested decision-making of this type was known as exchange theory where it 'assume[s] that the decision to have a child or to forgo parent-hood is the result of rational decisions based upon the social, economic, and emotional costs and benefits, as compared to the alternatives' (p. 192). Kim expressed this as 'weighing up the pros and cons of me personally having a child and not being emotionally equipped to deal with that.' The women's comments supported this assertion by advocating the necessity of an emotionally, financially, and physically stable environment to raise children. They acknowledged that they did not want to provide for a 
child on the basis that one of these elements was missing. This considered decision not to have children contradicts the common stereotype of childless women as being hedonistic, selfish, child-like, immature, and irresponsible (Gillespie, 2000, Kelly, 2009, KoropeckyjCox, \& Pendell, 2007; Letherby, 2002; Rowlands \& Lee, 2006).

In addition, the women described the commitment of time, personal energy, and responsibility associated with motherhood as something to be considered very seriously and they did not aspire to take that on. Lynn gave an example that typified the women's stance: 'I take the role very seriously, I think it's very, the most important [role] that anyone ever does is to raise a child, you have lots of responsibilities, I don't think I was prepared to take on that responsibility.' Additionally, Pippa indicated the need for certainty in wanting children and she viewed uncertainty from either partner as a major reason to not have a child:

We both feel instinctively that you needed to feel fairly certain that you wanted children in order to have children. Our motivation for our decision extends from the fact that we feel that having children is a huge responsibility and we didn't think that we could take that responsibility on with the feeling of I'm not sure if I want children. Until one of us felt really strongly about doing it, we wouldn't do it.

Half of the women spoke about the freedom their choice enabled and considered it a key reason for their choice. The women believed the ability to travel, to have options and to experience the world and self without compromise was essential to their way of life. There was a sense of continual potential in what or who they could be. Pippa captured this by saying, 'I can go and do anything I want to do and be anything I want to be because I don't have kids.' Amanda concurred with 'I suppose I feel lucky, I have the freedom to explore myself and my life.' They were able to engage in work commitments and not feel as if they had to be elsewhere to meet the needs of others. Motherhood was also viewed as time consuming, a burden and was not equated with freedom, which supports previous research 
regarding the cultural construction of 'good' motherhood as intensive, all-consuming, and self-sacrificing (Caputo, 2007). Candice, married to a man with children, described:

Mothers are slightly consumed because when the kids are here everything is drained and it's all about superficial stuff, driving kids around - so you cross the surface of life. Whereas because I don't have that I think that for me, life can be a lot deeper, from a spiritual point of view and also just from an enjoyment point of view, much more freedom, more spontaneous.

Freedom was also seen as a necessary component for their career as they were unfettered in their ability to devote their time and attention to what they perceived as an important role in giving back to the community.

\section{The Consequence}

The women reported that their choice to remain childfree was seen by others in their family and social networks as an act of social deviance. All women recounted experiences of being subjected to pressure due to their choice. Pressure ranged from their own internal expectations of acceptable behaviour and their perceptions of what others thought, to overt statements and behaviours from family, friends and the wider population, which was also established previously (DeOllos \& Kapinus, 2002; Mueller \& Yoder, 1999). Some women described adopting strategies to manage the pressure. For example, Karen was happy for people to assume that her niece was her daughter when they were out shopping together. These stigma management behaviours were also identified by Park (2002) and Kelly (2009) in their studies of voluntarily childless women.

While the childfree choice opposes pronatalism (Koropeckyj-Cox et al., 2007), Kim reported being subjected to its power at a young age by her father. She described, 'Education was not considered a priority by my father - you're just a female. You're just a female! All you're going to do with your life is grow up, get married, and have children. That's all I was 
going to do.' Karen acknowledged the pronatalist pressure when a grandfather-in-law constantly demanded, 'you must have children, you must have children!' Most participants recognised that they had strayed from the expectation of fitting in, to meet a man, marry and have children and instead felt pressure, particularly when peers were starting families. For example, Candice stated:

I think back then I was trying to fit into society by doing the right thing, so getting married, having children, getting a career were all part of that structure, but there's a slow realisation as I got a bit older, that I never fitted that mould.

Karen recounted going through the process of having medical tests in her early 30 s to see whether she was able to have children before coming to the realisation that she was responding to an expectation because it 'was a biological duty' and that 'I don't think we should have to be sheep.'

The women often found that friends, acquaintances, and family disbelieved or viewed their choice as temporary which was also found by Gillespie (2000) and Kelly (2009). While Jocelyn report that her mother asserted, 'That's okay, you can have a fabulous life if you don't have children,' all the women reported facing negative comments. There was the suggestion their choice was not definitive or acceptable, the women were young, they had not yet experienced the maternal urge and they would change their mind. Jocelyn reported often hearing, 'You'll turn 30 and the maternal instinct will kick in, don't shut the door too soon' while Lynn stated emphatically 'But I haven’t changed my mind. No.' Julie reported women saying, 'You know you're still young, you could feel it [maternal urge] one day' while Kim, who placed her choice in the context of not being financially stable, heard 'if you really wanted children you would have had them.'

Women who had cemented their choice by a surgical procedure were patronised despite their definitive action (see also Kelly, 2009). Amanda's aunt pleaded with, 'oh give it 
another six months, I can't believe you're going to do this' while Julie, whose husband had a vasectomy, experienced her mother's denial who believed her choice to be 'the biggest mistake of my life' and wanted her 'to freeze my eggs.' Empowered by her choice, Jocelyn asserted that the decision for her husband and herself to undergo surgical procedures (vasectomy and tubal ligation, respectively) 'was a reflection of the equality of the decision' also described by Scott (2009).

The women also intimated that they had been judged unfairly due to their choice and it was as if there was something 'wrong' with them. For example, Candice recounted hearing comments intimating she was 'not a woman unless I've had children,' while Amy shared she had faced, 'oh, don't bother, Amy's not maternal, not interested in kids, is a career woman.' Amy captured the common perception of deviating from the norm with 'You're not the same, you're different, you're weird, you don't make the same choices, you're not natural, you're not normal.' This is consistent with the stereotypical and negative views of childless women reported in the literature (Gillespie, 2000; Mollen, 2006; Shaw, 2011).

In addition to family pressure, the women described pressure from others in their social networks. They described some peers viewing their choice as 'selfish' (Jocelyn, Pippa), a view supported by previous research (Hird \& Abshoff; 2000; Letherby, 2002). This often left the women feeling hurt, misunderstood, and socially-excluded. Some of the women attempted to find humour in these experiences. For example, Candice asserted, 'I actually think that what parents do, they try and encourage you to have children so you can join them on the dark side' while Pippa described:

We joke about this conspiracy theory. All of our married friends have children and they go 'oh when are you having kids, when are you having kids, you've got to do it, it's the best thing you'll ever do'. And we're looking at them, they're tired, they've 
got no social life, they've got no money, they're really struggling and we're looking and going 'umm, not anytime soon.'

Discrimination in the workplace was encountered by some women, mainly in the form of being expected to work longer hours, weekends or school holidays, and cover for other women who 'had' to leave early to attend to children's needs. This discrimination was also found by Burkitt (2009) and Mollen (2006) in their studies of voluntarily childfree women's experience of stigmatisation. Of course, however, working mothers are also discriminated against in favour of childfree colleagues (Correll, Bernard, \& Paik, 2007). Our sample reported wanting others to realise that they had family responsibilities, just in a different form. Discrimination also occurred due to choices that challenged other people's perception of what was acceptable behaviour for childfree women. Jocelyn reported: I gave up working in 2000. I just turned 40 and just felt I needed to step out of the workplace for a while. Once they [people] established I wasn't dying of a terminal illness, I didn't have a job, I wasn’t raising children, [then] I was just being a burden on society. Some people couldn't handle that, a few friends didn't speak to me for several months, my parents and parents-in-law didn't know how to explain it to their friends. Some understood, some thought I was just being wasteful and not doing anything worthwhile. So the whole children bit and how you're contributing if you're not raising the next generation kicks up again. And so that year off was fabulous for me ... was really a nice chance to challenge some of those 'defined by what you do' things. But being a mother was one of those acceptable reasons for not working.

\section{No Regret}

None of the women reported experiencing any regret in their voluntary childfree status. They all indicated contentment in their choice as they viewed their lives as full and 'just different' (Candice, Amanda, Lynn, Kim) to those who had chosen parenthood. They 
were proud of their identity as childless women and engaged in generative activities in their careers, volunteer work, and involvement in their extended families. This desire contradicts the stereotype of the selfish, childfree woman (Gillespie, 2000, 2003; Kelly, 2009) and suggests the women are fulfilling the developmental stage of generativity by contributing to the betterment of others (Cwikel et al., 2006). All women engaged in volunteer work and/or were employed in the helping professions and all asserted the importance of engaging in meaningful work that helped people and contributed to the community. For example, some of the women reported having more energy, time, and the ability to give more of themselves to these pursuits because they did not have children. Pippa admitted that her volunteer activities linked directly to her experience of societal pressure to have children:

I felt that I had to give something back because I didn't want to be seen as selfish. I did volunteer work for other reasons as well. I did it because I was trying to avoid 'oh she doesn't have kids' so I think at the time I did feel that I needed to give something back.

Through consequence of choice, the women in this study felt they challenged the 'natural' role of women by rejecting motherhood (Gillespie, 2000; Mollen, 2006). When questioned about their maternal instincts, all women asserted not having experienced the phenomenon. Four women suggested that it may be expressed through the love they felt towards their animals. Four women reported its manifestation in the workplace. For example, Jocelyn stated:

I guess working with teams, one of the things I enjoy is being in a position where I can actually create an environment where someone can grow, learn, deal with something, feel safe, feel nurtured. So my leadership models are all around creating safe environments for people with clear boundaries, [and] lots of reinforcement about the positives. 
Importantly, none of the women believed that their womanhood had been compromised because they were not mothers.

In contemplating the future, only Karen expressed apprehension about who would look after her in old age. Three women reported that they had made 'pacts' (Candice, Jocelyn, Amy) with family members and friends to receive support and care in later life. Three others had a strong belief that they were self sufficient and had considered arrangements that would meet their needs, and this is borne out by research showing that older women without children experience a productive older adulthood (Cwikel et al., 2006). For example, Candice stated, 'I've made financial provisions and I don't expect anybody to look after me in my old life, in my old age; I'll look after myself.' Seven women conveyed strong views that there was 'no guarantee' that children could be relied upon to be caretakers in old age and believed this to be a myth as well as an inappropriate reason to have children. Cathy believed it to be 'selfish' while Candice thought people were 'just conning themselves' if they thought their children would be their caretakers. Pippa summarised this view:

Let's say you have children. Who's to say: (a) that they'll out live you, and (b) that they'll want to like you? You know, people say to me 'oh but you know when you have kids around you, then you have grandchildren, and then they'll look after you'. And I'm thinking, will they? There is no guarantee; I have looked after a lot of elderly people whose kids don't want to know them.

\section{Conclusion}

Our aim was to explore the reasons for and consequences of Australian women's choice to remain childfree. This is an increasingly important topic given that the number of childfree women is growing worldwide. The qualitative approach captured the women's subjective experiences and assists in developing our understanding of their motivations and experiences. These women resisted the hegemonic pronatalist ideology and the related 
conflation of woman with mother. Despite having to manage stigma and discrimination, the participants described their choice to remain childfree as positive and allowed them alternative ways to express generativity. In contrast to social norms, our research, as well as the research of others, demonstrates that childless women can be psychological well-adjusted without becoming mothers.

The research findings contribute to the existing literature by highlighting the role voluntary childfree women have in giving back to the community. The women's involvement in generative activities of volunteering and/or their profession contradicts the existing negative stereotype and supposition that childless women do not pass through this Erickson's (1963) important life stage. Further, the women regarded the choice to have children as a serious proposition with its associated responsibilities. The adoption of a rational, mature thought process in regards to their decision also challenges the existing negative stereotypical view of childfree women.

It is important to consider the strengths and limitations of the study. Strengths of this study include the articulation of the childless choice in an Australian sample and our attention to personal reflexivity in describing our perspectives on the topic (Parker, 2004). However, given the increasing numbers of women choosing to remain childfree across many industrialised nations these results have implications beyond our Australian cohort. All women clearly articulated their intention to remain childfree whereas little previous research has established the clear identification of absolute commitment to a childfree lifestyle versus the possibility of future births (Abma \& Martinez, 2006; Gillespie, 2000; Tanturri \& Mencarini, 2008). However, childbearing intentions and practices may change with circumstances such as unplanned pregnancy, a relationship breakdown, and infertility. Given that there is often an intersection between circumstance and choice (Jeffries \& Konnert, 2002; Kelly, 2009; Shaw, 2011), it is impossible to know if the women had freely chosen to not 
have children or if the idea of choice was retro-fitted to their situation. Additionally, the use of snowball sampling may be a limitation as it yielded predominately white, Englishspeaking, middle-class women. However, the findings complement that reported in Europe (e.g., Gillespie, 2003; Shaw, 2011; Tanturri \& Mencarini, 2008) and North America (e.g, Abma \& Martinez, 2006; Mollen, 2006; Park, 2002, 2005).

As an exploratory study, the findings provide a springboard for further research investigating voluntary childlessness with a larger and more diverse sample. Areas for additional future research include the experience of voluntarily childfree men (Park, 2005), particularly in regard to societal expectations of childfree men pertaining to fatherhood and masculinity (Dykstra \& Clarke, 2007); exploring how couples choose to remain childfree (Carmichael \& Whittaker, 2007); and the extent to which each individual in a marriage or partnership influences the choice (Mollen, 2006). Exploring these areas would create a richer understanding of the childfree choice.

In conclusion, the broad aim of this study was to explore voluntary childlessness in women in order to develop a greater understanding of women's choice to remain childfree. The women reported childhood influences as significant in shaping their decision-making processes and demonstrated the childfree choice as a complex decision that contain commonalities amongst the cohort, but which was also particular to each woman. This is important because it highlights the need for ongoing examination of the experience of childfree women and men to more fully understand this growing cohort. 


\section{References}

Abma JC, and Martinez GM (2006) Childlessness among older women in the United States: Trends and profiles. Journal of Marriage and Family 68:1045-1056.

Australian Bureau of Statistics (2000) Births Australia 2000 (Cat. No. 3301). Canberra, Australia: Author.

Becker CS (1992) Living and relating: An introduction to phenomenology. Newbury Park, CA: Sage.

Burkitt E (2000) The baby boon: How family-friendly America cheats the childless. New York: The Free Press.

Callan VJ (1987) The personal and marital adjustment of mothers and of the voluntarily and involuntarily childless wives. Journal of Marriage and the Family 49: 847-856.

Caputo V (2007) She's from a 'good family': Performing childhood and motherhood in a Canadian private school setting. Childhood 14: 173-192.

Carmichael GA, and Whittaker A (2007) Choice and circumstance: Qualitative insights into contemporary childlessness in Australia. European Journal of Population 23: 111143.

Chancey L, and Dumais SA (2009) Voluntary childlessness in marriage and family textbooks, 1950-2000. Journal of Family History 34: 206-223.

Correll SJ, Bernard S, and Paik I (2007). Getting a job: Is there a motherhood penalty? American Journal of Sociology 112: 1297-339.

Cwikel J, Gramotnev H, and Lee C (2006) Never-married childless women in Australia: Health and social circumstances in older age. Social Science and Medicine 62: 19912001.

DeOllos IY, and Kapinus CA (2002) Aging childless individuals: Suggestions for new directions in research. Sociological Inquiry 72: 72-80. 
Dykstra PA, and Hagestad GO (2007) Childlessness and parenthood in two centuries:

Different roads - different maps? Journal of Family Issues 11: 1518-1532.

Erikson EH (1963) Childhood and society. New York: Norton.

Giles D, Shaw RL, and Morgan W (2009) Representations of voluntary childlessness in the UK press, 1990-2008. Journal of Health Psychology 14: 1218-1228.

Gillespie R (1999) An examination of the reasons for and implications of women choosing to be childless in today's society. Reproductive Health Matters 7: 43-48.

Gillespie R (2000) When no means no: Disbelief, disregard and deviance as discourses of voluntary childlessness. Women's Studies International Forum 23: 223-234.

Gillespie R (2003) Childfree and feminine: Understanding the gender identity of voluntarily childless women. Gender and Society 17: 122-136.

Gregg M (2011). Do your homework. Feminist Media Studies 11: 73-81.

Heaton TB, Jacobson CK, and Holland K (1999) Persistence and change in decisions to remain childless. Journal of Marriage and the Family 61: 531-539.

Hird MJ, and Abshoff K (2000) Women without children: A contradiction in terms? Journal of Comparative Family Studies 31: 347-366.

Jeffries S, and Konnert C (2002) Regret and psychological well-being among voluntarily and involuntarily childless women and mothers. International Journal of Aging and Human Development 54: 89-106.

Kelly M (2009) Women's voluntary childlessness: A radical rejection of motherhood? Women's Studies Quarterly 37: 157-172.

Koropeckyj-Cox T, and Pendell G (2007) The gender gap in attitudes about childlessness in the United States. Journal of Marriage and Family 69: 899-915. 
Koropeckyj-Cox T, Romano V, and Moras A (2007) Through the lens of gender, race, and class: Students' perceptions of childless/childfree individuals and couples. Sex Roles 56: $415-428$.

Lee C, and Gramotnev H (2006) Motherhood plans among young Australian women. Journal of Health Psychology 11: 5-20.

Letherby G (2002) Childless and bereft? Stereotypes and realities in relation to 'voluntary' and 'involuntary’ childlessness and womanhood. Sociological Inquiry 72: 7-20.

Macklin, ED (1980) Nontraditional family forms: A decade of research. Journal of Marriage and the Family 42: 905-921.

Mauthner NS, and Doucet A (2003) Reflexive accounts and accounts of reflexivity in qualitative data analysis. Sociology 37: 413-431.

Mueller KA, and Yoder JD (1999) Stigmatization of non-normative family size status. Sex Roles 41: 901-919.

Mollen D (2006) Voluntarily childfree women: Experiences and counseling considerations. Journal of Mental Health Counseling 28: 269-282.

Moustakas C (1994) Phenomenological research methods. Thousand Oaks, CA: Sage.

Park K (2002) Stigma management among the voluntarily childless. Sociological Perspectives 45: 21-45.

Park K (2005) Choosing childlessness: Weber's typology of action and motives of the voluntarily childless. Sociological Inquiry 75: 372-402.

Parker I (2004) Criteria for qualitative research in psychology. Qualitative Research in Psychology 1:95-106.

Rothauff T, and Cooney TM (2008) The role of generativity in psychological well-being: Does it differ for childless adults and parents? Journal of Adult Development 15: 148159. 
Rowland DT (2007) Historical trends in childlessness. Journal of Family Issues 28: 13111337.

Rowlands I, and Lee C (2006) Choosing to have children or choosing to be childfree: Australian students' attitudes towards the decisions of heterosexual and lesbian women. Australian Psychologist 41: 55-59.

Scott LS (2009) Two is enough: A couples guide to living childless by choice. Berkeley, CA: Seal Press.

Seccombe K (1991) Assessing the costs and benefits of children: Gender comparisons among childfree husbands and wives. Journal of Marriage and the Family 53:191-202.

Shaw RL (2011) Women's experiential journey towards voluntary childlessness: An interpretative phenomenological analysis. Journal of Community and Applied Social Psychology 21: 151-163.

Somers MD (1993) A comparison of voluntarily childfree adults and parents. Journal of Marriage and the Family 55: 643-650.

Tanturri ML, and Mencarini L (2008) Childless or childfree? Paths to voluntary childlessness in Italy. Population and Development Review 34: 51-77.

Vinson C, Mollen D, and Smith NG (2010) Perceptions of childfree women: The role of perceivers' and targets' ethnicity. Journal of Community and Applied Social Psychology 20: 426-432.

Willis JW (2007) Foundations of qualitative research. Thousand Oaks, CA: Sage.

Younane S (2008) 'Working families' and the 'opportunity society': Political rhetoric in the 2007 Australia federal election campaign. Communication, Politics and Culture 41(2): 62-83. 